\title{
Hyponatremia associated with demyelinating disease of the nervous system
}

\author{
Daisuke Mori - Ikue Nagayama • Yoshito Yamaguchi · \\ Seiji Itano • Natsuko Imakita $\cdot$ Masanobu Takeji • \\ Atsushi Yamauchi
}

Received: 6 August 2012/ Accepted: 9 October 2012/Published online: 30 January 2013

(C) Japanese Society of Nephrology 2012

\begin{abstract}
A 63-year-old man was diagnosed with periodontitis and underwent tooth extraction. Several days later, he suffered a high fever, ischuria, a change in personality, and disorientation. A urologist examined him and found severe hyponatremia $(117 \mathrm{mEq} / \mathrm{L})$, and he was then transferred to our hospital. On admission, physical findings revealed dysfunction of the bladder and bowel, altered mental status, and hypovolemia. Blood chemistry showed serum sodium of $120 \mathrm{mEq} / \mathrm{L}$, a serum urate of $1.4 \mathrm{mg} / \mathrm{dL}$, urinary $\mathrm{Na}$ of $61 \mathrm{mEq} / \mathrm{L}$, and fractional urate excretion of $16 \%$. Examination of the cerebrospinal fluid (CSF) showed monocytosis. Magnetic resonance imaging (MRI) of the brain and spinal cord showed multiple lesions characterized by hyperintensity on $\mathrm{T} 2$-weighted sequences, suggesting demyelinating disease. His sodium concentration normalized 3 days after volume replacement therapy, and his altered mental status along with the dysfunction of the bladder and bowel were promptly improved after the initiation of high-dose glucocorticoids. Additionally, the abnormal lesions on MRI markedly decreased. This clinical course led to the likely diagnosis of acute disseminated encephalomyelitis (ADEM). Hyponatremia in neurologically injured patients is usually attributed to the syndrome of inappropriate antidiuretic hormone (SIADH) or cerebral salt-wasting syndrome (CSWS). In the present patient, the uric acid level remained low and uric acid excretion remained elevated despite correction of the hyponatremia, which suggested CSWS. The differentiation of CSWS from SIADH is difficult but critically important due to the fact that the disorders
\end{abstract}

D. Mori · I. Nagayama · Y. Yamaguchi · S. Itano ·

N. Imakita $\cdot$ M. Takeji $\cdot$ A. Yamauchi $(\bowtie)$

Division of Nephrology, Osaka Rosai Hospital,

1179-3 Nagasone-cho, Sakai, Osaka 591-8025, Japan

e-mail: ayamauchi@orh.go.jp are managed differently. Coexistence of ADEM and CSWS has rarely been reported.

Keywords Cerebral salt-wasting syndrome . Syndrome of inappropriate antidiuretic hormone . Hyponatremia - Acute disseminated encephalomyelitis

\section{Introduction}

Hyponatremia is the most frequent electrolyte disorder in patients with neurologic disease. The syndrome of inappropriate antidiuretic hormone (SIADH) is frequently diagnosed in this clinical setting, but cerebral salt-wasting syndrome (CSWS) is another important diagnosis to consider. Distinction between these two conditions can sometimes be difficult [1]. Described in this report is an elderly patient with demyelinating disease of the central nervous system who presented with hyponatremia and was diagnosed with CSWS based on his clinical course.

\section{Case report}

A 63-year-old man was admitted to our hospital in February 2012 for the examination and treatment of hyponatremia. He had been in good health until a week previously, when he was diagnosed with periodontitis and had his tooth extracted. Several days later, he visited a urologist accompanied by a fever, headache, and dysuria. A urinary catheter was inserted and laboratory findings showed marked hyponatremia $(117 \mathrm{mEq} / \mathrm{L})$. He was then transferred to our hospital.

On admission, he exhibited a change in personality and disorientation (Glasgow Coma Scale: E3V4M6). His body weight and height were $57 \mathrm{~kg}$ and $162 \mathrm{~cm}$, respectively. 
Table 1 Laboratory data on admission

\begin{tabular}{|c|c|c|c|c|c|}
\hline \multicolumn{2}{|c|}{ Blood analysis } & \multirow{2}{*}{$\begin{array}{l}\text { BUN } \\
\mathrm{Cr}\end{array}$} & \multirow{2}{*}{$\begin{array}{l}11 \mathrm{mg} / \mathrm{dL} \\
0.4 \mathrm{mg} / \mathrm{dL}\end{array}$} & \multicolumn{2}{|l|}{ Urinalysis } \\
\hline WBC & $11600 / \mu \mathrm{L}$ & & & $\mathrm{pH}$ & 6.5 \\
\hline Neutro & $84.4 \%$ & UA & $1.4 \mathrm{mg} / \mathrm{dL}$ & glu & $2+$ \\
\hline Lymph & $7.3 \%$ & $\mathrm{Ca}$ & $8 \mathrm{mg} / \mathrm{dL}$ & prot & $1+$ \\
\hline Mono & $8.3 \%$ & $\mathrm{P}$ & $2.1 \mathrm{mg} / \mathrm{dL}$ & $\mathrm{OB}$ & $2+$ \\
\hline Eos & $0 \%$ & $\mathrm{Mg}$ & $2.6 \mathrm{mg} / \mathrm{dL}$ & $\mathrm{UP} / \mathrm{Cr}$ & 0.20 \\
\hline Baso & $0 \%$ & CRP & $0.43 \mathrm{mg} / \mathrm{dL}$ & U-TP & $0.20 \mathrm{~g} /$ day \\
\hline $\mathrm{RBC}$ & $492 \times 10^{4} / \mu \mathrm{L}$ & TSH & $0.684 \mu \mathrm{IU} / \mathrm{mL}$ & $\mathrm{RBC}$ & 50-99 /HPF \\
\hline $\mathrm{Hb}$ & $15.3 \mathrm{~g} / \mathrm{dL}$ & FT3 & $2.21 \mathrm{pg} / \mathrm{mL}$ & WBC & $1-4 / \mathrm{HPF}$ \\
\hline Het & $45.6 \%$ & FT4 & $1.4 \mathrm{ng} / \mathrm{dL}$ & Hyaline cast & 5-9/WF \\
\hline Plt & $233 \times 10^{3} / \mu \mathrm{L}$ & BNP & $28.7 \mathrm{pg} / \mathrm{mL}$ & Urine osmolarity & $439 \mathrm{mOsm} / \mathrm{L}$ \\
\hline \multicolumn{2}{|c|}{ Chemical analysis } & AVP & $1.7 \mathrm{pg} / \mathrm{mL}$ & $\mathrm{u}-\mathrm{Na}$ & $61.1 \mathrm{mEq} / \mathrm{L}$ \\
\hline $\mathrm{Na}$ & $120 \mathrm{mEq} / \mathrm{L}$ & Aldosterone & $42 \mathrm{pg} / \mathrm{mL}$ & $\mathrm{u}-\mathrm{K}$ & $15.4 \mathrm{mEq} / \mathrm{L}$ \\
\hline $\mathrm{K}$ & $2.5 \mathrm{mEq} / \mathrm{L}$ & PRA & $0.8 \mathrm{ng} / \mathrm{mL} / \mathrm{h}$ & $\mathrm{u}-\mathrm{Cl}$ & $104.8 \mathrm{mEq} / \mathrm{L}$ \\
\hline $\mathrm{Cl}$ & $82 \mathrm{mEq} / \mathrm{L}$ & Cortisol & $23.4 \mu \mathrm{g} / \mathrm{dL}$ & u-UA & $72.5 \mathrm{mg} / \mathrm{dL}$ \\
\hline $\mathrm{TP}$ & $6.5 \mathrm{~g} / \mathrm{dL}$ & ACTH & $8.3 \mathrm{pg} / \mathrm{mL}$ & $\mathrm{u}-\mathrm{Cr}$ & $128.1 \mathrm{mg} / \mathrm{dL}$ \\
\hline Alb & $3.9 \mathrm{~g} / \mathrm{dL}$ & \multicolumn{2}{|c|}{ Arterial blood gas } & FENa & $0.16 \%$ \\
\hline AST & $16 \mathrm{U} / \mathrm{L}$ & $\mathrm{pH}$ & 7.49 & FEUA & $16.2 \%$ \\
\hline ALT & $22 \mathrm{U} / \mathrm{L}$ & $\mathrm{pCO}_{2}$ & $35.5 \mathrm{mmHg}$ & NAG & $30 \mathrm{U} / \mathrm{L}$ \\
\hline \multirow[t]{2}{*}{$\mathrm{LDH}$} & $211 \mathrm{U} / \mathrm{L}$ & $\mathrm{pO}_{2}$ & $80.4 \mathrm{mmHg}$ & $\beta 2-\mathrm{MG}$ & $873 \mu \mathrm{g} / \mathrm{L}$ \\
\hline & & $\mathrm{HCO}_{3}$ & $26.7 \mathrm{mmol} / \mathrm{L}$ & & \\
\hline
\end{tabular}

Physical examination revealed a blood pressure of $140 / 85 \mathrm{mmHg}$, heart rate of 89 beats/min, and body temperature of $37.5^{\circ} \mathrm{C}$. He showed no signs of an enlarged jugular vein, postural hypotension, pitting edema, or dehydration of the mucous membranes, but exhibited decreased skin turgor. Neurological examination revealed bladder and rectal disturbance, as well as altered mental status. The rest of the physical examination was unremarkable. His hemoglobin was $15.3 \mathrm{~g} / \mathrm{dL}$, hematocrit $45.6 \%$, and white cell count $11600 / \mu \mathrm{L}$. Blood chemistry showed $\mathrm{Na}$ of $120 \mathrm{mEq} / \mathrm{L}, \mathrm{K}$ of $2.5 \mathrm{mEq} / \mathrm{L}, \mathrm{Cl}$ of $82 \mathrm{mEq} /$ $\mathrm{L}$, blood urea nitrogen of $11 \mathrm{mg} / \mathrm{dL}$, creatinine of 0.4 $\mathrm{mg} / \mathrm{dL}$, uric acid of $1.4 \mathrm{mg} / \mathrm{dL}$, and albumin of $3.9 \mathrm{~g} / \mathrm{dL}$. Serum C-reactive protein was $0.43 \mathrm{mg} / \mathrm{dL}$. Blood gas analysis revealed a $\mathrm{pH}$ of $7.49, \mathrm{pCO}_{2}$ of $35.5 \mathrm{mmHg}, \mathrm{pO}_{2}$ of $80.4 \mathrm{mmHg}$, and $\mathrm{HCO}_{3}^{-}$of $26.7 \mathrm{mmoL} / \mathrm{L}$. Urinalysis showed a urinary protein of $0.20 \mathrm{~g} / \mathrm{gCr}$, urinary red blood cells of 50-99/high-power field, urinary $\mathrm{Na}$ of $61 \mathrm{mEq} / \mathrm{L}$, urinary $\mathrm{K}$ of $15 \mathrm{mEq} / \mathrm{L}$, urinary $\mathrm{Cl}$ of $105 \mathrm{mEq} / \mathrm{L}$, and fractional excretion of uric acid of $16 \%$ (Table 1). A chest $\mathrm{X}$-ray displayed a low cardiothoracic ratio of $38.8 \%$, and ultrasound measurement of the inferior vena cava revealed the diameter to be $7 \mathrm{~mm}$.

Intracranial disease was suspected as the cause of the altered mental status. Brain computed tomography (CT) was normal, but magnetic resonance imaging (MRI) showed multiple areas of hyperintensity in T2-weighted images, including the left optic nerve, hypothalamus, thalamus, peridium, medulla oblongata, and cervical cord, suggestive of demyelinating disease (Fig. 1). Cerebrospinal fluid (CSF) examination revealed an opening pressure of $24 \mathrm{~cm} \mathrm{H}_{2} \mathrm{O}$, glucose of $72 \mathrm{mg} / \mathrm{dL}$, protein of $80 \mathrm{mg} / \mathrm{dL}$, and total cell count of 525 cells $/ \mathrm{mm}^{3}$ (monocytes $99 \%$ ). Gram staining and fungal staining were negative. Bacterial and viral cultures of the CSF and polymerase chain reaction studies for cytomegalovirus (CMV), Epstein-Barr virus (EBV), herpes simplex virus (HSV), and human herpes virus (HHV)-6 were all negative. These results reduced the possibility for infectious encephalitis to be a cause of illness.

Regarding his hyponatremia, hypothyroidism and hypoadrenalism were excluded due to biochemical analysis of the serum. Arginine vasopressin (AVP) was normal, despite low serum osmolality. In addition, his brain natriuretic peptide (BNP) was slightly elevated and his plasma renin activity and aldosterone were at the lower limit of normal in the context of dehydration (Table 1). After admission, his appetite improved slightly and his urine osmolarity decreased. Because he used an analgesic to ease toothache before admission, this drug might have some effect on the sodium concentration. Three days after admission, his serum sodium rose to $125 \mathrm{mEq} / \mathrm{L}$ without any infusion of sodium.

Neuroimaging showed areas of demyelization, typical of an autoimmune inflammatory disease such as acute disseminated encephalomyelitis (ADEM), but acute infectious encephalitis could not be completely ruled out. Therefore, the patient was started on high-dose glucocorticoids and 


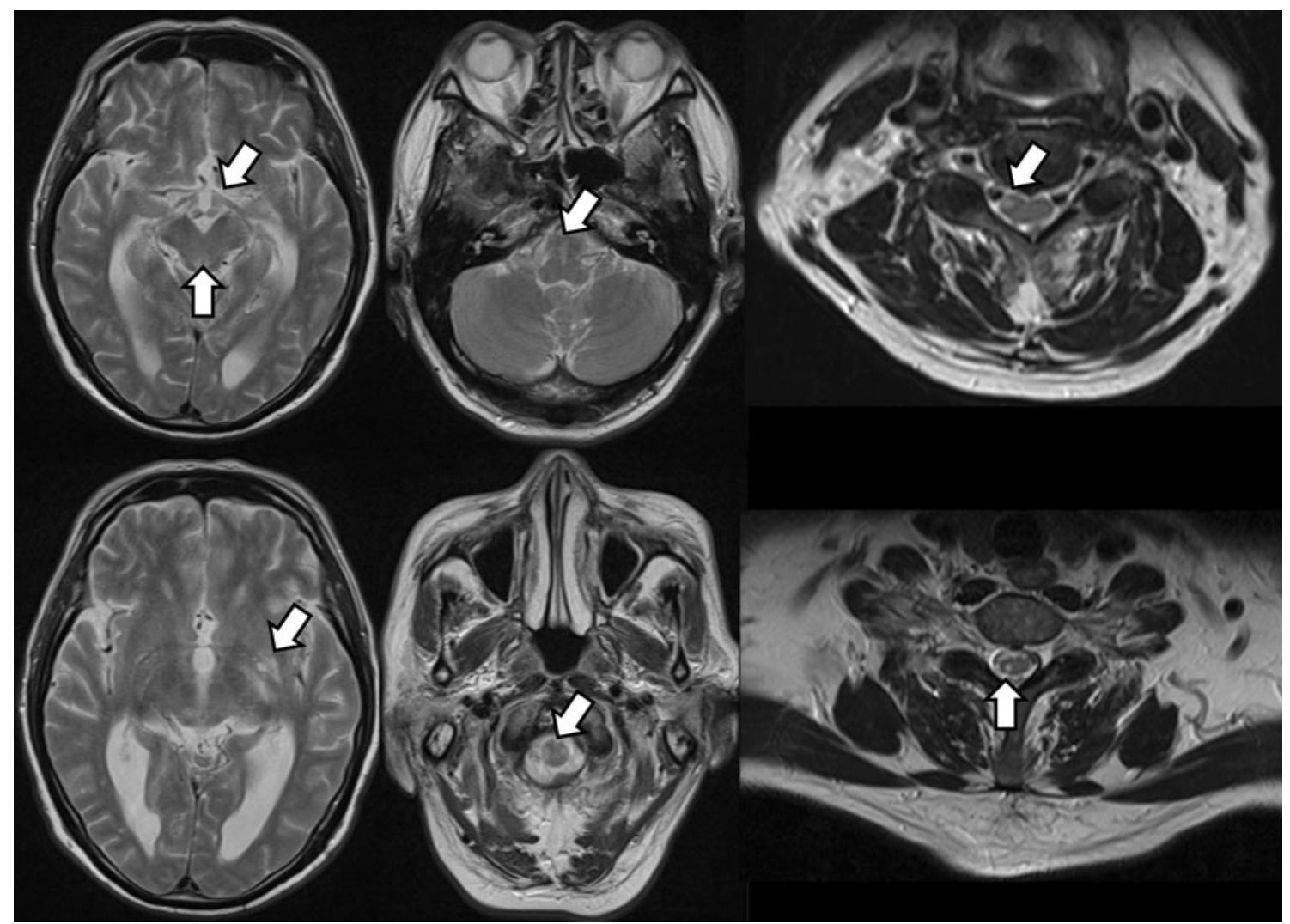

Fig. 1 T2-weighted magnetic resonance imaging (MRI) shows multiple areas of hyperintensity, including in the left optic nerve, hypothalamus, thalamus, peridium, medulla oblongata, and cervical cord (arrows)

Fig. 2 Clinical course

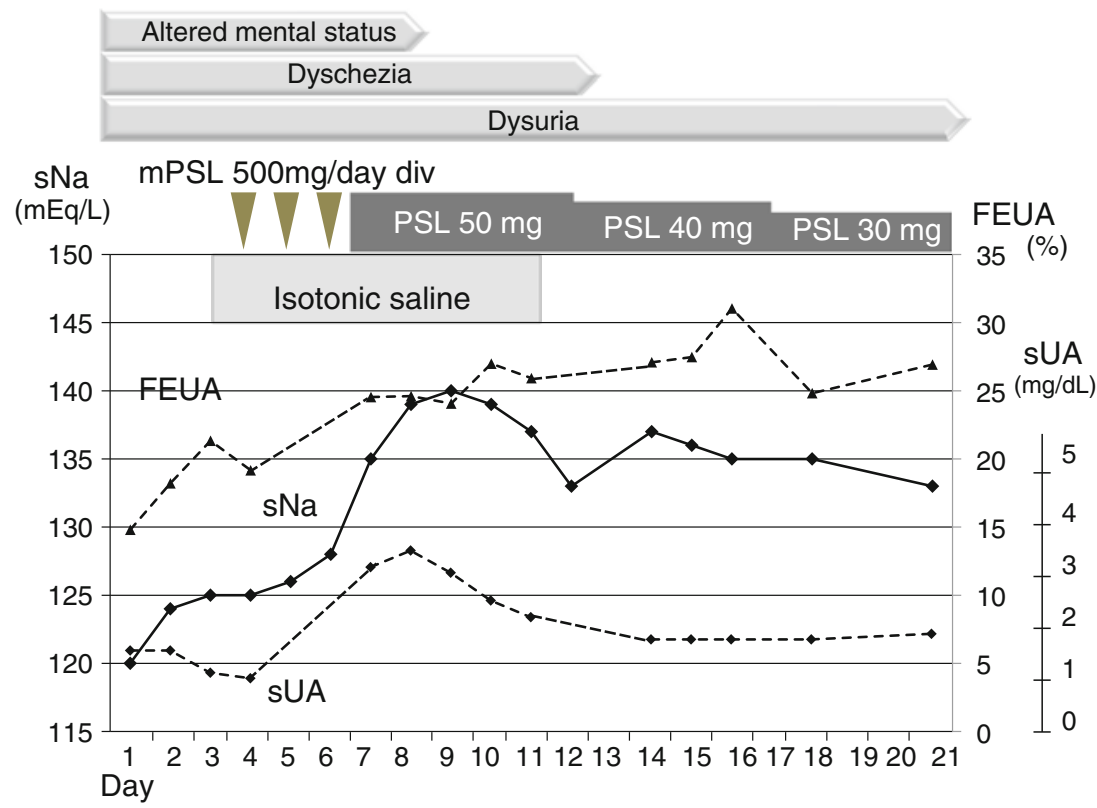

acyclovir ( $1.5 \mathrm{~g} /$ day). He received $0.5 \mathrm{~g} /$ day of intravenous methylprednisolone for 3 days, and then continued therapy with progressively decreasing doses of oral prednisolone (Fig. 2). In addition, intravenous infusion of isotonic saline was started at the same time that glucocorticoids were introduced, since it was thought that his body fluid volume indicated dehydration. After 4 days of therapy, his consciousness returned to normal (Glasgow Coma Scale: 
E4V5M6), CSF total cell count decreased to 85 cells $/ \mathrm{mm}^{3}$, and plasma sodium concentration returned to normal $(139 \mathrm{mEq} / \mathrm{L})$. After 8 days of therapy, the administration of isotonic saline was discontinued, his dyschezia improved, and CSF total cell count decreased to 43 cells/ $\mathrm{mm}^{3}$. MRI carried out after 12 days of therapy showed that the abnormal lesions had markedly disappeared. However, his uric acid level remained low and uric acid excretion remained elevated, despite correction of the hyponatremia. Oral prednisolone was gradually reduced to $30 \mathrm{mg} /$ day and he was discharged.

\section{Discussion}

In the present patient, the temporal relationship between his febrile episode and the onset of acute multifocal neurologic deficits coupled with the demonstration of demyelinating features on MRI strongly suggested the clinical diagnosis of ADEM [2]. ADEM appears to be an autoimmune disorder of the central nervous system that typically presents as a monophasic disorder. It is often preceded by a viral or bacterial infection, but the pathogenesis is not fully understood [3]. The mainstay of treatment for ADEM is high-dose glucocorticoids. Most patients have a complete recovery if prompt treatment is initiated [2, 3]. An important alternative diagnosis to ADEM is multiple sclerosis (MS). CSF adenosine deaminase (ADA) was normal, and there was no evidence of CSF oligoclonal banding or myelin basic protein in the present report. These results suggest that there was a lower possibility for MS to be the cause of his altered mental status. At initial presentation, however, the two disorders cannot be distinguished with absolute certainty. Therefore, prolonged follow-up is required in order to establish a diagnosis.

At initial presentation, in addition to hyponatremia with a low plasma osmolality, the patient had the following features: cerebral disease with normal adrenal and thyroid function, findings suggestive of volume depletion, slightly elevated plasma BNP, high urinary sodium concentration, and a low serum uric acid concentration (due to urate wasting in the urine). Three days later, his serum sodium slightly rose as his appetite was improved. After fluid replacement with isotonic saline, his sodium concentration quickly improved and plasma BNP also normalized, but his hypouricemia and increased fractional excretion of urate was persistent.

Regarding the cause of hyponatremia in the present patient, it is proposed that the hypouricemia and elevated fractional urate excretion with hyponatremia was more consistent with either SIADH or CSWS [4]. CSWS is defined as a renal loss of sodium during intracranial disorders, leading to hyponatremia and a decrease in extracellular fluid volume [5]. CSWS has been most often described in patients with subarachnoid hemorrhage [6]. It has also been reported in patients with infectious meningitis, encephalitis, central nervous system tumors, as well as following central nervous system surgery [7-9]. Rare cases have been described to have intracranial autoimmune inflammatory diseases such as ADEM [10]. Maesaka et al. $[11,12]$ carefully studied CSWS and noted that this condition can occur in patients without cerebral disease, such as acquired immunodeficiency syndrome (AIDS), cancer, or pulmonary disease. For this reason, they favor the term "renal salt-wasting syndrome" (RSWS), rather than CSWS. Concerning the mechanism of hyponatremia, SIADH results from persistently high levels of vasopressin. In patients with CSWS, renal salt-wasting is the primary defect, which is followed by volume depletion that, in turn, leads to a secondary rise in vasopressin. Thus, fluid restriction is the treatment of choice in SIADH, while the treatment of CSWS consists of vigorous sodium and volume replacement. Given the divergent nature of the treatment and the potential for improper selection of fluid therapy that can worsen the underlying clinical condition, it is of paramount importance for the clinician to be able to recognize and differentiate between these two entities [1, 13]. CSWS and SIADH share many similar laboratory and clinical findings at initial presentation. The fundamental difference between the two processes is extracellular fluid (ECF) volume status [12]. ECF volume tends to be slightly increased in SIADH, whereas it is decreased in CSWS. Unfortunately, it is usually difficult for the physician to confirm from a bedside observation whether a patient has a low ECF volume, since physical examination and laboratory signs used to support a volume-contracted state provide limited sensitivity for the assessment of hypovolemia [14]. Although the central venous pressure (CVP) is a very useful estimate of intravascular volume status, CVP measurement can be also inaccurate [15]. In addition, an increase in fractional excretion of phosphate has been reported in CSWS but not in SIADH [11]. A compilation of the main characteristics to distinguish CSWS from SIADH is shown in Table $2[5,11]$. In the present patient, clinical findings suggested a volume-contracted state without clear evidence, but the laboratory data did not show an increase in fractional excretion of phosphate. So, it was initially thought that differentiating CSWS from SIADH would be difficult in this case. The key differentiation proposed is that, despite the correction of hyponatremia, the uric acid level remains low and uric acid excretion remains elevated in patients with CSWS [4, 6]. In the present patient, the saline infusion provided prompt correction of the hyponatremia, but the persistence of hypouricemia, as well as increased fractional urate excretion after correction of the hyponatremia, suggested CSWS over SIADH. 
Table 2 Differential diagnosis of cerebral salt-wasting syndrome (CSWS) and syndrome of inappropriate antidiuretic hormone (SIADH)

\begin{tabular}{llll}
\hline & SIADH & CSW & Present case \\
\hline Extracellular sodium volume & $\rightarrow$ to $\uparrow$ & $\downarrow$ & $\downarrow$ (probably) \\
Urine osmolality & $\uparrow$ & $\uparrow$ & $\uparrow$ \\
Urine sodium concentration & $\uparrow$ & $\uparrow$ & $\uparrow$ \\
Serum uric acid & $\downarrow$ & $\downarrow$ & $\downarrow$ \\
Initial FEUA & $\uparrow$ & $\uparrow$ & $\uparrow$ \\
FE phosphate & $\rightarrow$ & $\uparrow$ & $\rightarrow$ \\
Hematocrit & $\rightarrow$ & $\rightarrow$ or $\uparrow$ & $\rightarrow$ \\
Serum bicarbonate & $\rightarrow$ or $\downarrow$ & $\uparrow$ & $\uparrow$ \\
Central venous pressure & $\rightarrow$ to $\uparrow$ & $\downarrow$ & Not measured \\
BNP & $\rightarrow$ & $\uparrow$ & $\uparrow$ \\
\hline
\end{tabular}

The mechanism by which cerebral disease might lead to renal salt-wasting is poorly understood. Two putative mechanisms are the interference of sympathetic input to the kidney and central elaboration of a circulating natriuretic factor $[13,16]$. It has yet to be demonstrated how intracranial disease impairs neural input to the kidney. The rostral ventrolateral medulla (RVLM) oblongata region contains neurons that have a key role in determining peripheral sympathetic activity. Increased activity of RVLM neurons is transmitted to the intermediolateral cell column at each level of the spinal cord, where peripheral sympathetic nerves to the heart, arterioles, and kidneys are activated [5]. In the present patient, neural imaging showed multiple areas of demyelinating lesions, including the medulla oblongata and cervical cord, suggesting the possibility of impaired efferent pathways of sympathetic nerves. According to this theory, loss of adrenergic tone to the nephron leads to a decrease in renin secretion, thereby, causing decreased levels of aldosterone and decreased sodium reabsorption at the proximal convoluted tubule [5]. This mechanism could explain why the present patient demonstrated suppressed renin and aldosterone levels in spite of volume contraction. In addition, decreased sympathetic tone leads to dilatation of the afferent arteriole, causing increased glomerular filtration of plasma and sodium [5].

The second theory is that a circulating factor that impairs renal tubular sodium reabsorption is released in patients with brain injury. Among the various natriuretic peptides, BNP may be the most probable candidate for the mediation of CSWS [16]. In the present patient, plasma BNP was slightly elevated at presentation. BNP is primarily released by the cardiac ventricles in response to increased ECF, but can also be secreted by the brain (cerebral cortex, thalamus, cerebellum, pons, and hypothalamus) [17]. One plausible hypothesis is that direct damage to cortical and subcortical structures containing BNP leads to inadvertent release of hormone directly into the circulation [5]. In addition, it is also suggested that BNP is released from hormone-producing neurons in the brain in response to increased intracranial pressure $[13,16]$. In the present patient, demyelinating lesions included the thalamus and hypothalamus, areas which both contain BNP. This hypothesis could explain why intracranial lesions led to renal salt-wasting in the present patient.

The relationship between serum urate, fractional urate excretion, and hyponatremia has yet to be clarified. The sodium-linked transport of urate into the cell across the luminal membrane of the proximal tubular cell could occur as follows. Urate reabsorption is indirectly coupled to sodium transport by an electroneutral anion exchanger. Anions, such as chloride and organic acid anions, first enter the proximal tubule cell through a sodium-dependent cotransport and move back into the tubule lumen in exchange for uric acid via urate transporter 1 (URAT1) [18]. It is possible that the natriuretic factor might indirectly decrease urate reabsorption through the anion exchanger by decreasing sodium reabsorption, competing with urate for the anion exchanger.

In conclusion, described in this paper is a case of hyponatremia in a patient with cerebral disease. It is important to consider CSWS in addition to SIADH in patients who present with hyponatremia and an intracranial process. The essential point for differentiation of the two conditions is volume status on the first encounter. In addition, levels of natriuretic peptides and changes in the fractional excretion of uric acid may help differentiate between the two conditions.

Conflict of interest All the authors have declared no competing interest.

\section{References}

1. Gutierrez OM, Lin HY. Refractory hyponatremia. Kidney Int. 2007;71:79-82.

2. Menge T, Hemmer B, Nessler S, Wiendl H, Neuhaus O, Hartung HP, Kieseier BC, Stüve O. Acute disseminated encephalomyelitis: an update. Arch Neurol. 2005;62:1673-80.

3. Tenembaum S, Chitnis T, Ness J, Hahn JS; International Pediatric MS Study Group. Acute disseminated encephalomyelitis. Neurology. 2007;68:S23-36.

4. Maesaka JK, Gupta S, Fishbane S. Cerebral-salt wasting syndrome: does it exist? Nephron. 1999;82:100-9.

5. Yee AH, Burns JD, Wijdicks EF. Cerebral salt wasting: pathophysiology, diagnosis, and treatment. Neurosurg Clin $\mathrm{N}$ Am. 2010;21:339-52.

6. Sherlock M, O’Sullivan E, Agha A, Behan LA, Rawluk D, Brennan P, Tormey W, Thompson CJ. The incidence and pathophysiology of hyponatraemia after subarachnoid haemorrhage. Clin Endocrinol (Oxf). 2006;64:250-4.

7. Sakarcan A, Bocchini J Jr. The role of fludrocortisone in a child with cerebral salt wasting. Pediatr Nephrol. 1998;12:769-71. 
8. Brookes MJ, Gould TH. Cerebral salt wasting syndrome in meningoencephalitis: a case report. J Neurol Neurosurg Psychiatry. 2003;74:277.

9. Vespa P. Cerebral salt wasting after traumatic brain injury: an important critical care treatment issue. Surg Neurol. 2008;69:230-2.

10. Fujiki F, Tsuboi Y, Hori T, Yamada T. Aseptic meningitis as initial presentation of acute disseminated encephalomyelitis. J Neurol Sci. 2008;272:129-31.

11. Bitew S, Imbriano L, Miyawaki N, Fishbane S, Maesaka JK. More on renal salt wasting without cerebral disease: response to saline infusion. Clin J Am Soc Nephrol. 2009;4:309-15.

12. Maesaka JK, Imbriano LJ, Ali NM, Ilamathi E. Is it cerebral or renal salt wasting? Kidney Int. 2009;76:934-8.

13. Palmer BF. Hyponatraemia in a neurosurgical patient: syndrome of inappropriate antidiuretic hormone secretion versus cerebral salt wasting. Nephrol Dial Transplant. 2000;15:262-8.
14. McGee S, Abernethy WB 3rd, Simel DL. The rational clinical examination. Is this patient hypovolemic? JAMA. 1999;281:1022-9.

15. Marik PE, Baram M, Vahid B. Does central venous pressure predict fluid responsiveness? A systematic review of the literature and the tale of seven mares. Chest. 2008;134:172-8.

16. Berendes E, Walter $M$, Cullen $P$, Prien $T$, Van Aken $H$, Horsthemke J, Schulte M, von Wild K, Scherer R. Secretion of brain natriuretic peptide in patients with aneurysmal subarachnoid haemorrhage. Lancet. 1997;349:245-9.

17. Takahashi K, Totsune K, Sone M, Ohneda M, Murakami O, Itoi $\mathrm{K}$, Mouri T. Human brain natriuretic peptide-like immunoreactivity in human brain. Peptides. 1992;13:121-3.

18. Maesaka JK, Fishbane S. Regulation of renal urate excretion: a critical review. Am J Kidney Dis. 1998;32:917-33. 